\title{
SISTEM PAKAR ANALISA KERUSAKAN SEPEDA MOTOR MATIC DENGAN METODE DEMPSTER SHAFER DAN PEMROGRAMAN PYTHON
}

\author{
Hikmatulloh' ${ }^{1}$, Dede Wintana ${ }^{2}$, Susilawati ${ }^{3}$ \\ Universitas Bina Sarana Informatika \\ Jl. Kramat Raya No. 98, Jakarta Pusat. Telp. (021) 54376399 Fax. (021) 54376298 \\ hikmatul0808@bsi.ac.id11, dede.dwe@bsi.ac.id², susilawati.ssl@bsi.ac.id³
}

\begin{abstract}
Motorcycle automotive industry of automatic transmission (Matic Motorcycle) is currently experiencing significant developments, producers continue to innovate for the products they produce for the fulfillment of the community's need for the use of automatic transmission motorbikes. However, the limitations of the time and place of the workshop and the lack of public knowledge about the damage to their motorbikes have become a problem that is currently arising. The development of a system to analyze damage to an automatic transmission motorbike is indeed necessary, so that it will be easier for motor owners to know the damage to their vehicles more effectively and efficiently. This expert system will help provide symptomatic diagnosis results managed in the system, using the dempster shafer method and symptoms of damage that have been given the value of symptoms obtained from experts. This expert system was designed and built using the Python programming language.
\end{abstract}

Keywords : Expert System, Dempster Shafer, Damage Automatic transmission motorbike, python.

\begin{abstract}
Abstrak
Industri otomotif sepeda motor bertransmisi automatic (motor matic) saat ini terus mengalami perkembangan yang signifikan, produsen terus berinovasi untuk produk yang mereka hasilkan demi terpenuhinya kebutuhan masyarakat akan penggunaan sepeda motor bertransmisi automatic. Namun keterbatasan waktu dan tempat bengkel serta kurangnya pengetahuan masyarakat akan kerusakan sepeda motornya menjadi permasalahan yang timbul saat ini. Pengembangan system untuk menganalisa kerusakan pada sepeda motor bertransmisi automatic memang diperlukan, sehingga akan mempermudah pemilik motor mengetahui kerusakan kendaraannya lebih efektif dan efisien. Sistem pakar ini akan membantu memberikan hasil diagnosa gejala yang dikelola di dalam sistem, dengan menggunakan metode dempster shafer dan gejala kerusakan yang sudah diberikan nilai gejala yang didapat dari pakar. Sistem pakar ini dirancang dan dibangun menggunakan bahasa pemrograman python.
\end{abstract}

Kata Kunci: Sistem Pakar, Dempster Shafer, Kerusakan Motor Matic, python. 


\section{PENDAHULUAN}

Alat transportasi telah menjadi kebutuhan dasar masyarakat dalam melakukan aktifitas sehari-hari, kegiatan ekonomi, pendidikan, maupun kegiatan sosial sangat memerlukan sarana penggerak dari suatu tempat ke tempat lain yang hampir tidak mungkin dilakukan jika tidak menggunakan alat transportasi. Sebagian besar masyarakat sekarang telah menjadikan sepeda motor sebagai sarana transportasi utama, menggunakan sepeda motor dapat menghemat waktu dan biaya menuju tempat tujuan[1].

Asosiasi Industri Sepeda Motor Indonesia (AISI) mengumumkan data penjualan sepeda motor yang dirilis dari di bulan pertama 2018, dalam data wholesales (dari pabrik ke dealer), penjualan sepeda motor domestik pada Januari 2018 sebesar 482.537 unit, atau mengalami kenaikan dari 473.879 unit pada Januari 2017. Penjualan kuda besi pada Januari 2018 masih didominasi skutik (motor matic) sebesar 83,58 persen.

Permasalahan yang timbul mengingat tingginya penggunaan sepeda motor matic saat ini yakni sebagian besar pengguna tidak memiliki kemampuan melakukan perbaikan terhadap kerusakan sepeda motornya. Pengguna sepeda motor lebih mempercayakan masalah kerusakan motor pada mekanik bengkel, akan tetapi jam kerjanya terbatas[2]. Dengan semua aktivitas yang padat dan penuh khususnya di kota - kota besar, telah menuntut masyarakat untuk mengerjakan segala sesuatunya dengan cepat dan tepat.

Sistem pakar merupakan program yang mampu menyimpan pengetahuan dan kaidah dari domain pakar yang khusus. Sistem pakar dapat membantu seorang yang awam atau tidak ahli dalam suatu bidang tertentu akan dapat menjawab pertanyaan, menyelesaikan masalah dan mengambil keputusan yang biasanya dilakukan oleh seorang pakar[3]. Dengan penerapan sistem pakar, perawatan maupun perbaikan motor bisa dilakukan sendiri, tanpa harus datang ke bengkel dengan membawa kendaraan tersebut.

Metode yang akan digunakan dalam sistem pakar ini yaitu metode dempster shafer, teori Dempster-Shafer adalah suatu teori matematika untuk pembuktian berdasarkan belief functions and plausible reasoning (fungsi kepercayaan dan pemikiran yang masuk akal), yang digunakan untuk mengkombinasikan potongan informasi yang terpisah (bukti) untuk mengkalkulasi kemungkinan dari suatu peristiwa[4]. Dengan penerapan metode ini diharapkan mampu memberikan informasi kepada pengguna motor bertransmisi automatic tentang kerusakan sepeda motornya.

\section{METODE PENELITIAN}

\subsection{Metode Dampster Shafer}

Metode yang digunakan adalah metode Dampster Shafer yang merupakan salah satu metode ketidakpastian. Perhitungan ketidakpastian diperlukan dalam 
sistem, agar diagnosa dapat memberikan keyakinan seperti layaknya si pakar. Peranan sistem tidak sepenuhnya menggantikan si pakar, namun merupakan sistem yang dapat membantu untuk melakukan pekerjaan seperti halnya pemikiran si pakar, dalam bidang yang tak terbatas waktu dan area konsultasi[5].

Metode dempster shafer pertama kali diperkenalkan oleh Dempster, yang melakukan percobaan model ketidakpastian dengan range probabilities dari pada sebagai probabilitas tunggal. Kemudian pada tahun 1976 Shafer mempublikasikan teori Dempster itu pada sebuah buku yang berjudul Mathematical Theory of Evident. Dempster-Shafer Theory of Evidence, menunjukkan suatu cara untuk memberikan bobot kenyakinan sesuai fakta yang dikumpulkan. Pada teori ini dapat membedakan ketidakpastian dan ketidaktahuan. Teori Dempster-Shafer adalah representasi, kombinasi dan propogasi ketidakpastian, dimana teori ini memiliki beberapa karakteristik yang secara instutitif sesuai dengan cara berfikir seorang pakar, namun dasar matematika yang kuat.[6].

Teori dempster-shafer dituliskan sebagai Belief dan Plausibility[7]:

Belief menunjukan ukuran kekuatan evidence dalam mendukung suatu hipotesis. Plausibility menunjukkan keadaan yang bisa dipercaya. Keterkaitan antara plausibility dan belief dapat dituliskan. $\mathrm{Pl}(\mathrm{H})=1$-Bel $(\mathrm{H})$. Dalam teori dempster-shafer diasumsikan bahwa hipotesis-hipotesis yang digunakan dikelompokkan ke dalam suatu lingkungan (environment) tersendiri yang biasa disebut himpunan semesta pembicaraan dari sekumpulan hipotesis dan berikan notasi $\theta$. Selain itu dikenal juga probabilitas fungsi densitas (m) yang menunjukkan besarnya kepercayaan evidence terhadap hipotesis tertentu.

Adapun, fungsi belief dan plausibility dapat diformulasikan sebagai berikut:

$\operatorname{Bel}_{(x)}=\sum \mathrm{m}_{(y)}$

$\operatorname{Pls}_{(\mathrm{x})}=1-\operatorname{Bel}_{\left(x^{\prime}\right)}=1-\sum \mathrm{m}_{\left(x^{\prime}\right)}$

Dimana:

$\operatorname{Bel}_{(\mathrm{x})}=\operatorname{Belief}_{(\mathrm{x})}$

$\operatorname{Pls}(\mathrm{x})=$ Plausibility $(\mathrm{x})$

$\mathrm{m}_{(\mathrm{x})}=$ mass function dari $(\mathrm{x})$

$\mathrm{m}_{(\mathrm{y})}=$ mass function dari $(\mathrm{y})$

Plausibility juga bernilai 0 sampai 1 , jika kita yakin akan $x^{\prime}$ maka dapat dikatakan Belief $\left(\mathrm{x}^{\prime}\right)=1$ sehingga dari rumus di atas nilai Pls $(x)=0$.

Berikut rumus dari teori dempster shafer :

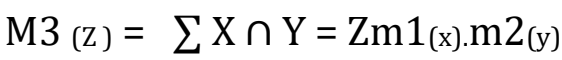

$1-\sum X \cap Y=\theta m 1_{(x)} \cdot m 2_{(y)}$ 
Keterangan :

$\mathrm{m} 1=$ densitas untuk gejala pertama

$\mathrm{m} 2$ = densitas gejala kedua

m3 = kombinasi dari kedua densitas diatas

$\theta=$ semesta pembicaraan dari sekumpulan hipotesis ( $X^{\prime}$ dan $\left.Y^{\prime}\right)$

$\mathrm{X}$ dan $\mathrm{y}=$ subset dari $\mathrm{Z}$

$\mathrm{X}^{\prime}$ dan $\mathrm{y}^{\prime}=$ subset dari $\theta$

\subsection{Bahasa Pemrograman Python}

Python merupakan salasatu bahasa pemrograman yang dinamis dan mempunyai sistem manajemen memori yang otomatis seperti bahasa pemrograman lainnya. Python biasanya digunakan melalui script atau kode-kode, meskipun bahasa pemrograman ini lebih banyak dimanfaatkan untuk yang umumnya tidak banyak menggunakan script. [8]

Python telah menjadi populer untuk aplikasi-aplikasi yang berkaitan dengan bisnis, santifik, dan akademik dan sangat cocok untuk programmer pemula. Ada banyak alasan mengapa Python sukses dan berkembang. Python memiliki sintaksis yang jauh lebih ringkas dari bahasa-bahasa pemrograman populer yang ada saat ini seperti Java, C, dan C++. Oleh karena itu, python jauh lebih mudah untuk dipelajari. Di samping itu, program-program python dapat di coba pada IDE (Integrated Development Environment) yang interaktif seperti spyder. [9] 


\section{PEMBAHASAN DAN HASIL}

\subsection{Pembahasan}

Dari hasil wawancara dengan tiga orang pakar di bidangnya, dapat diambil sebuah data mengenai kerusakan dan gejala yang ditimbulkannya dengan masingmasing bobot yang telah diberikan oleh pakar tersebut. Data kerusakan dan gejala dapat dilihat pada tabel berikut ini.

Tabel 1. Data kerusakan dan gejala pada motor matic

\begin{tabular}{cllc}
\hline No & \multicolumn{1}{c}{ Kerusakan } & \multicolumn{1}{c}{ Gejala } & Bobot \\
\hline 1 & [K1] Kerusakan pada Piston & [G4] Suara mesin kasar & 0,9 \\
2 & [K2] Kerusakan pada Van Belt & [G4] Suara mesin kasar & 0,9 \\
3 & [K3] Kerusakan pada Busi & [G1] Keluar asap dari knalpot & 0,9 \\
4 & [K3] Kerusakan pada Busi & [G2] Di starter manual sulit & 0,9 \\
5 & [K3] Kerusakan pada Busi & [G3] Tarikan berat & 0,7 \\
6 & [K4] Kerusakan pada Injektor & [G2] Di starter manual sulit & 0,9 \\
7 & [K4] Kerusakan pada Injektor & [G3] Tarikan berat & 0,8 \\
8 & [K5] Kerusakan pada Roller & [G1] Keluar asap dari knalpot & 0,7 \\
9 & [K6] Kerusakan pada Klep & [G2] Di starter manual sulit & 0,8 \\
10 & [K6] Kerusakan pada Klep & [G3] Tarikan berat & 0,9 \\
11 & [K6] Kerusakan pada Klep & [G4] Suara mesin kasar & 0,7 \\
12 & [K7] Kerusakan pada CVT & [G3] Tarikan berat & 0,8 \\
\hline
\end{tabular}

Berikut hasil dari perhitungan dalam menganalisa jenis kerusakan motor matic menggunakan metode dempster shafer, disajikan dalam bentuk dibawah ini.

Tabel 2. Perhitungan dempster shafer

\begin{tabular}{|c|c|c|c|}
\hline \multicolumn{2}{|c|}{$\begin{array}{l}\text { Kerusakan pada } \\
\text { Piston }\end{array}$} & \multirow{2}{*}{$\begin{array}{c}\mathrm{M}_{[\mathrm{G} 4][\mathrm{K} 2]} \\
0,900 \\
0,81\end{array}$} & \multirow{2}{*}{$\begin{array}{c}\mathrm{M}_{[\varnothing]} \\
0,1 \\
0,09\end{array}$} \\
\hline $\mathrm{M}_{[\mathrm{G} 4][\mathrm{K} 1]}$ & $: 0,9$ & & \\
\hline $\mathrm{M}_{[\varnothing]}$ & $: 0,1$ & 0,09 & 0,01 \\
\hline \multirow{2}{*}{\multicolumn{2}{|c|}{$\begin{array}{l}\text { Kerusakan pada } \\
\text { Van Belt }\end{array}$}} & Bel & $\mathrm{Pla}$ \\
\hline & & 0,999 & 0,01 \\
\hline $\mathrm{M}_{[\mathrm{G} 1][\mathrm{K} 3]}$ & $: 0,9$ & 0,891 & 0,009 \\
\hline $\mathrm{M}_{[\varnothing]}$ & $: \quad 0,1$ & 0,099 & 0,001 \\
\hline \multirow{2}{*}{\multicolumn{2}{|c|}{$\begin{array}{l}\text { Kerusakan pada } \\
\text { Busi }\end{array}$}} & Bel & Pla \\
\hline & & 0,999 & 0,001 \\
\hline $\mathrm{M}_{[\mathrm{G} 2][\mathrm{K} 3]}$ & $: 0,9$ & 0,8991 & 0,0009 \\
\hline $\mathrm{M}_{[\varnothing]}$ & $: 0,1$ & 0,0999 & $1 \mathrm{E}-04$ \\
\hline \multicolumn{2}{|c|}{ Kerusakan pada } & Bel & Pla \\
\hline
\end{tabular}




\begin{tabular}{|c|c|c|c|}
\hline \multicolumn{2}{|c|}{ Busi } & 0,9999 & $1 \mathrm{E}-04$ \\
\hline $\mathrm{M}_{[\mathrm{G} 3][\mathrm{K} 3]}$ & 0,7 & 0,69993 & 7E-05 \\
\hline $\mathrm{M}_{[\varnothing]}$ & 0,3 & 0,29997 & 0,00003 \\
\hline \multirow{2}{*}{\multicolumn{2}{|c|}{$\begin{array}{l}\text { Kerusakan pada } \\
\text { Busi }\end{array}$}} & Bel & Pla \\
\hline & & 0,997 & 0,00003 \\
\hline $\mathrm{M}_{[\mathrm{G} 2][\mathrm{K} 4]}$ & $: 0,9$ & 0,899973 & 0,000027 \\
\hline $\mathrm{M}_{[\varnothing]}$ & $: 0,1$ & 0,099997 & 0,000003 \\
\hline \multirow{2}{*}{\multicolumn{2}{|c|}{$\begin{array}{l}\text { Kerusakan pada } \\
\text { Injektor }\end{array}$}} & Bel & Pla \\
\hline & & 0,999997 & 0,000003 \\
\hline $\mathrm{M}_{[\mathrm{G} 3][\mathrm{K} 4]}$ & $: 0,8$ & 0,7999976 & 0,0000024 \\
\hline $\mathrm{M}_{[\varnothing]}$ & 0,2 & 0,1999994 & $6 \mathrm{E}-07$ \\
\hline \multirow{2}{*}{\multicolumn{2}{|c|}{$\begin{array}{l}\text { Kerusakan pada } \\
\text { Injektor }\end{array}$}} & Bel & Pla \\
\hline & & 0,994 & $6 \mathrm{E}-07$ \\
\hline $\mathrm{M}_{\text {[G1][K5] }}$ & $: 0,7$ & 0,69999958 & 0,00000042 \\
\hline $\mathrm{M}[\varnothing]$ & $: 0,3$ & 0,29999982 & 0,00000018 \\
\hline \multirow{2}{*}{\multicolumn{2}{|c|}{$\begin{array}{c}\text { Kerusakan pada } \\
\text { Roller }\end{array}$}} & Bel & Pla \\
\hline & & 0,998 & 0,00000018 \\
\hline $\mathrm{M}_{[\mathrm{G} 2][\mathrm{K} 6]}$ & $: 0,8$ & 0,799999856 & 0,000000144 \\
\hline $\mathrm{M}_{[\varnothing]}$ & $: 0,2$ & 0,199999964 & 0,000000036 \\
\hline \multirow{2}{*}{\multicolumn{2}{|c|}{$\begin{array}{c}\text { Kerusakan pada } \\
\text { Roller }\end{array}$}} & Bel & Pla \\
\hline & & 0,999999964 & 0,000000036 \\
\hline $\mathrm{M}_{[\mathrm{G} 3][\mathrm{K} 6]}$ & $: 0,9$ & 0,899999968 & 3,24E-08 \\
\hline $\mathrm{M}_{[\varnothing]}$ & 0,1 & 0,099999996 & $3,6 \mathrm{E}-09$ \\
\hline \multirow{2}{*}{\multicolumn{2}{|c|}{$\begin{array}{l}\text { Kerusakan pada } \\
\text { Klep }\end{array}$}} & Bel & Pla \\
\hline & & 0,996 & 3,6E-09 \\
\hline $\mathrm{M}_{[\mathrm{G} 4][\mathrm{K} 6]}$ & $: 0,7$ & 0,699999997 & 2,52E-09 \\
\hline $\mathrm{M}_{[\varnothing]}$ & $: 0,3$ & 0,299999999 & $1,08 \mathrm{E}-09$ \\
\hline \multirow{2}{*}{\multicolumn{2}{|c|}{$\begin{array}{l}\text { Kerusakan pada } \\
\text { Klep }\end{array}$}} & Bel & Pla \\
\hline & & 0,999999999 & $1,08 \mathrm{E}-09$ \\
\hline $\mathrm{M}_{[\mathrm{G} 3][\mathrm{K} 7]}$ & : 0,8 & 0,799999999 & $8,64 \mathrm{E}-10$ \\
\hline $\mathrm{M}_{[\varnothing]}$ & : 0,2 & 0,2 & $2,16 \mathrm{E}-10$ \\
\hline \multirow{2}{*}{\multicolumn{2}{|c|}{$\begin{array}{c}\text { Kerusakan pada } \\
\text { CVT }\end{array}$}} & Bel & Pla \\
\hline & & 1 & $2,16 \mathrm{E}-10$ \\
\hline
\end{tabular}

Dalam perhitungan metode dempster shafer untuk menentukan jenis kerusakan pada motor matic ini akan mengambil dari salasatu responden yang sedang mengalami kerusakan pada sepeda motornya. Dalam kasus ini responden mengalami dua gejala yang terjadi pada sepeda motor nya yaitu keluar asap dari knalpot [G1] dan distarter manual sulit [G2]. Pada gejala [G1] terdapat 2 
kemungkinan kerusakan yang terjadi pada sepeda motor matic yaitu kerusakan pada busi [K3] dan kerusakan pada Roller [K5], pada gejala ini memiliki nilai belief 0,9. Dan pada gejala [G2] terdapat 3 kemungkinan kerusakan yang terjadi pada sepeda motor matic yaitu kerusakan pada busi [K3], kerusakan pada Injektor [K4], kerusakan pada roller [K5], dan pada gejala ini memiliki nilai belief 0,8.

Nilai densitas gejala terhadap setiap kerusakan

[G1] : Kerusakan pada busi [K3] 0,9

Kerusakan pada Roller [K5] $\quad 0,7$

[G2] : Kerusakan pada busi [K3] 0,9

Kerusakan pada Injektor [K4] $\quad 0,9$

Kerusakan pada Roller [K5] $\quad 0,8$

a. Menentukan nilai M pada gejala [G1] keluar asap dari knalpot

$\begin{array}{ll}\mathrm{M}_{[\mathrm{K} 3]} & =0,9 \\ \mathrm{M}_{[\varnothing]} & =1-\left(\mathrm{M}_{[\mathrm{K} 3]}\right)=1-0,9=0,1 \\ \mathrm{M}_{[\mathrm{K} 5]} & =0,7 \\ \mathrm{M}_{[\varnothing]} & =1-\left(\mathrm{M}_{[\mathrm{K} 5]}\right)=1-0,7=0,3 \\ \mathrm{M}_{[\mathrm{K} 4]} & =0,9 \\ \mathrm{M}_{[\varnothing]} & =1-\left(\mathrm{M}_{[\mathrm{K} 3]}\right)=1-0,9=0,1 \\ \mathrm{M}_{[\mathrm{K} 5]} & =0,8 \\ \mathrm{M}_{[\varnothing]} & =1-\left(\mathrm{M}_{[\mathrm{K} 5]}\right)=1-0,8=0,2\end{array}$

Keluar asap dari knalpot [G1]

\begin{tabular}{|c|c|c|c|c|}
\hline \multirow{2}{*}{\multicolumn{3}{|c|}{ \# }} & $\mathrm{M}_{[\mathrm{K} 5]}$ & $\mathrm{M}_{[\emptyset]}$ \\
\hline & & & 0,7 & 0,3 \\
\hline $\mathrm{M}_{[\mathrm{K} 3]}$ & : & 0,9 & 0,63 & 0,27 \\
\hline $\mathrm{M}_{[\emptyset]}$ & : & 0,1 & 0,07 & 0,03 \\
\hline
\end{tabular}

$M_{[K 5]}=\frac{(0,65)+(0,07)+(0,27)}{1-0}=0,990$

$M_{[\varnothing]}=\frac{(0,03)}{1-0}=0,03$ 
b. Menentukan nilai M pada gejala [G2] distarter manual sulit

Distarter manual sulit [G2]

\begin{tabular}{|c|c|c|c|c|}
\hline & & & $\begin{array}{c}\mathrm{M}_{[\mathrm{K} 4]} \\
0,9\end{array}$ & $\begin{array}{c}\mathrm{M}_{[\varnothing]} \\
0,1\end{array}$ \\
\hline $\mathrm{M}_{[\mathrm{K} 3]}$ & : & 0,9 & 0,81 & 0,09 \\
\hline $\mathrm{M}_{[\varnothing]}$ & : & 0,1 & 0,09 & 0,01 \\
\hline
\end{tabular}

$\mathrm{M}_{[\mathrm{K} 4]}=\frac{(0,81)+(0,09)+(0,09)}{1-0}=0,99$

$M_{[\varnothing]}=\frac{(0,01)}{1-0}=0,01$

\begin{tabular}{|c|c|c|c|c|}
\hline \multicolumn{3}{|c|}{ \# } & $\begin{array}{c}\mathrm{M}_{[\mathrm{K} 6]} \\
0,8\end{array}$ & $\begin{array}{c}\mathrm{M}_{[\varnothing]} \\
0,2\end{array}$ \\
\hline $\mathrm{M}_{[\mathrm{K} 3-4]}$ & : & 0,99 & 0,792 & 0,198 \\
\hline $\mathrm{M}_{[\varnothing]}$ & : & 0,01 & 0,008 & 0,002 \\
\hline
\end{tabular}

$\mathrm{M}_{[\mathrm{K} 5]}=\frac{(0,792)+(0,008)+(0,198)}{1-0}=0,998$

$M_{[\varnothing]}=\frac{(0,002)}{1-0}=0,002$

Dari hasil perhitungan tersebut manunjukan bahwa kerusakan terjadi pada Roller dengan kode gejala [K5] yang menghasilkan nilai belief tertinggi sebesar 0,998 .

\subsection{Hasil}

Hasil merupakan suatu proses yang menerjemahkan desain ke dalam bentuk perangkat lunak secara utuh. Proses ini dilakukan untuk mengetahui apakah sistem yang dirancang dapat berjalan dengan baik berdasarkan perancangan sebelumnya[1]. Hasil dari pembahasan akan diterapkan dalam pemrograman 
menggunakan bahasa pemrograman python 3.7 dengan bantuan IDE spyder, berikut penjelasannya.

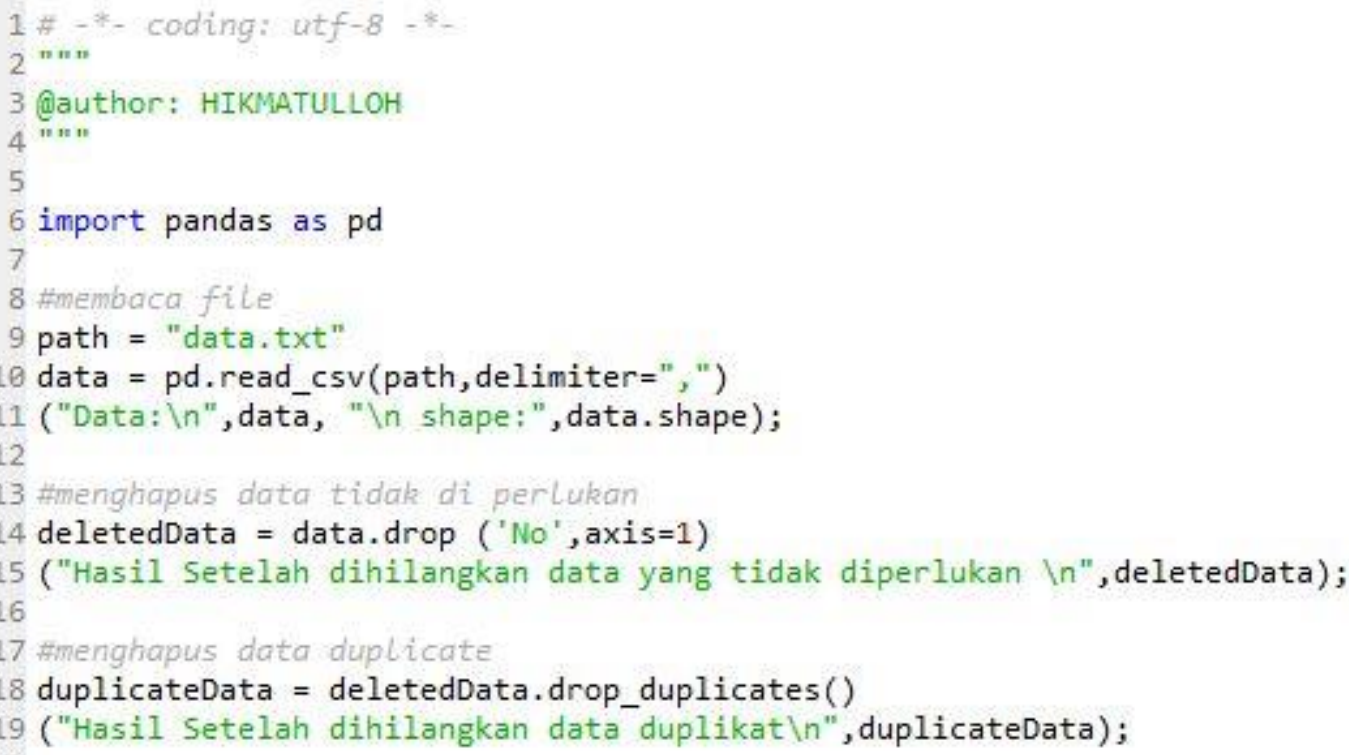

Gambar 1. Proses pengolahan data pakar

Gambar 1 menunjukan proses pengolahan data pakar, Dalam tahap ini dilakukan import package panda dengan menginisialkan menjadi "pd", setelah itu file data pakar dengan ekstensi txt dibaca dan dipanggil. Setelah data berhasil terpanggil maka dilakukan penghapusan data yang tidak diperlukan dalam pemrosesan pengolahan data, dan langkah terakhir pada proses ini yaitu mencari data duplikat dan menghapusnya.

Setelah didapatkan nilai belief dan plausibility dalam hal ini telah dicontohkan pada sub bab sebelumnya dengan mengambil salasatu kasus dari responden yang mengalamin mengalami dua gejala yang terjadi pada sepeda motor nya yaitu keluar asap dari knalpot [G1] dan distarter manual sulit [G2], maka langkah selanjutnya yaitu menghitung nilai densitas dari setiap nilai belief dan plausibility setiap gejala, berikut perhitungan nilai densitas dari metode dempster shafer: 
22 \#perhitungan metode dempster shafer

3 def var (b1, p1, b2, p2):

$m=((b 1 * b 2)+(p 1 * b 2)+(b 1 * p 2)) /(1-\theta)$

return $m$

bel1 $=0.99$

$\mathrm{pla} 1=0.01$

bel $2=0.8$

pla $2=0.2$

densitas $=\operatorname{var}($ bel1 $, \mathrm{pla} 1, \mathrm{be} 12, \mathrm{pla} 2)$

print ("\nE-BENGKEL CEK KERUSAKAN MOTOR MATIC")

print (" $============================$
print ("Nilai Densitas Sebesar", densitas)

if densitas $==0.900$ :

print("Kerusakan terjadi pada PISTON")

print("Solusi kerusakan : \n 1. Penggantian ring piston \n 2. Pembuangan aran

elif densitas $=0.999$ :

print("Kerusakan terjadi pada VANBELT")

print("Solusi kerusakan : \n 1. Jika Van belt terkontaminasi air atau debu $m$

elif densitas $=0.997$ :

print("Kerusakan terjadi pada BUSI")

print("Solusi kerusakan : \n 1. Lakukan pembersihan pada busi /n 2. Pecahkan

elif densitas $=0.994$ :

print("Kerusakan terjadi pada INJEKTOR")

print("Solusi kerusakan : \n 1. Bersihkan injektor, bisa anda gunakan carbon

elif densitas $=0.998$ :

print("Kerusakan terjadi pada ROLLER")

print("Solusi kerusakan : \n 1. buka baut sebagai penguncian rumah puli, dan

elif densitas $=0.996$ :

print("Kerusakan terjadi pada KLEP") else:

print("Solusi kerusakan : \n 1. Periksa klep oli dan minyak. In 2. Jika sala print("Kerusakan terjadi pada CVT")

print("Solusi kerusakan : \n 1. Siapkan kunci T ukuran 8 untuk membuka bak

1 print ("

2 print ("Terima Kasih")

63

Gambar 2. Perhitungan pengolahan dempster shafer

Tahap terakhir yaitu menguji dan melihat hasil dari implementasi program pengolahan data dan perhitungan algoritma yang akan di tampilkan pada gambar di bawah ini. 


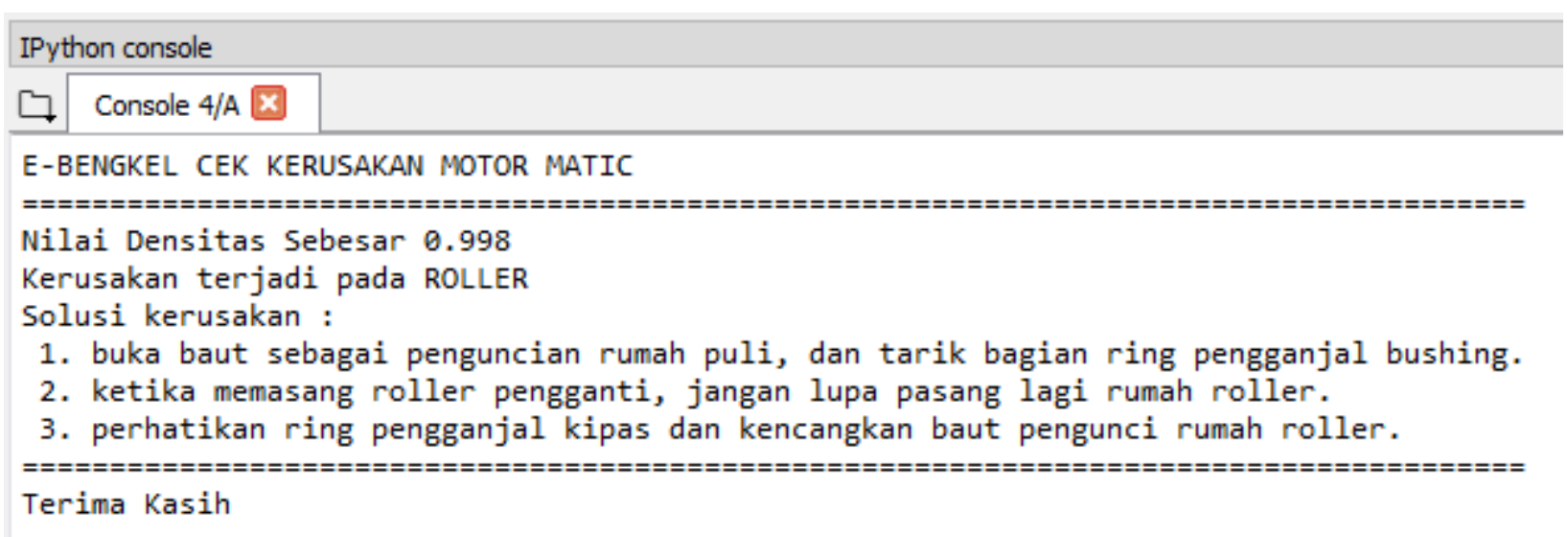

Gambar 3. Pengujian dan hasil dari program

\section{SIMPULAN}

Kesimpulan yang dapat diambil dari penerapan metode dempster shafer untuk sebuah sistem pakar analisa kerusakan sepeda motor bertransmisi automatic menggunakan bahasa pemrograman python 3.7 dengan bantuan IDE spyder ini dapat memberikan solusi yang dibutuhkan untuk masyarakat ketika mengalami kerusakan pada motor, khususnya sepeda motor bertransmisi automatic atau biasa disebut motor matic yang banyak digemari masyarakat. Dan diharapkan dengan dirancangnya sistem pakar ini dapat memudahkan masyarakat dalam mengetahui kerusakan motor dengan cara yang lebih efisien. Untuk pengembangan selanjutnya sistem pakar analisa kerusakan sepeda motor bertransmisi automatic ini dapat di implementasikan secara lebih baik lagi demi terpenuhinya kebutuhan masyarakat.

\section{DAFTAR PUSTAKA}

[1] R. Afnur, T. Sriwahyuni, and A. Hadi, "Rancang bangun aplikasi sistem pakar untuk diagnosis kerusakan sepeda motor matic menggunakan metode forward chaining," vol. 4, no. 2, 2016.

[2] I. Wiguna, A. S., \& Harianto, "SISTEM PAKAR DIAGNOSA KERUSAKAN SEPEDA MOTOR MATIC INJEKSI MENGGUNAKAN METODE FORWARD CHAINING BERBASIS ANDROID.," SMARTICS J., pp. 25-30, 2017.

[3] A. Wibowo, R. Afrian, and S. Bahri, "SISTEM PAKAR HUKUM PIDANA PENCURIAN MENGGUNAKAN," pp. 130-134.

[4] M. Iqbal and H. Aprilianto, "Diagnosa Kerusakan Sepeda Motor Vespa Menggunakan Metode Dempster Shafer Berbasis Android."

[5] M. Widyaningsih, "Sistem diagnosa penyakit tht pada balita menggunakan dempster 
shafer," vol. 3, pp. 29-38, 2018.

[6] A. Of et al., "Penerapan Metode Dempster Shafer Untuk Mendiagnosa Penyakit Dari Akibat Bakteri Treponema Pallidum," vol. 9, no. 3, pp. 180-189, 2017.

[7] M. Ihsan, F. Agus, and D. M. Khairina, "SISTEM DETEKSI PENYAKIT TANAMAN PADI," vol. 2, no. 1, 2017.

[8] R. M. Awangga, SISTEM INFORMASI GEOGRAFIS. Bandung: Kreatif Industri Nusantara, 2019.

[9] V. Siahaan and R. H. Sianipar, Konsep dan Implementai Pemrograman Python. SPARTA, 2019. 